\title{
Decreases of Life Expectancy Despite Decreases in Non-Communicable Disease Mortality: The Role of Substance Use and Socioeconomic Status
}

\author{
Jürgen Rehm ${ }^{a-f}$ Charlotte Probst ${ }^{a, f}$ \\ a Institute for Mental Health Policy Research, Centre for Addiction and Mental Health, Toronto, ON, Canada; \\ ${ }^{b}$ Campbell Family Mental Health Research Institute, Centre for Addiction and Mental Health, Toronto, ON, Canada; \\ 'Addiction Policy, Dalla Lana School of Public Health, University of Toronto, Toronto, ON, Canada; ${ }^{\mathrm{d}}$ Institute of \\ Medical Science, University of Toronto, Faculty of Medicine, Toronto, ON, Canada; ${ }^{e}$ Department of Psychiatry,

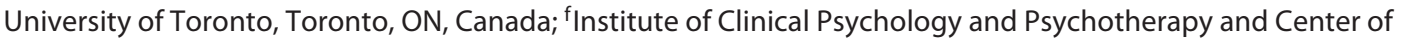 \\ Clinical Epidemiology and Longitudinal Studies (CELOS), Technische Universität Dresden, Dresden, Germany
}

\section{Keywords}

Alcohol use - Tobacco use · Illicit drug use - Mortality · Life expectancy · Socioeconomic status · United States

\begin{abstract}
With the epidemiological transition, causes of death shifted from communicable to non-communicable diseases (NCDs) and life expectancy increased, as these NCD deaths occurred later in life. However, in the United States, over the past years, life expectancy has been stagnating or decreasing despite decreasing NCD mortality rates. Analyses of the most important underlying causes of death with increasing premature mortality reveal that psychoactive substance use played a crucial role for these increases. Furthermore, it can be shown, that a high proportion of the increased premature mortality and decreased life expectancies happened in lower socio-economic strata. Substance use policies should thus focus on lowering the gap between substance-attributable mortality in higher versus lower socioeconomic strata.

(c) 2018 S. Karger AG, Basel
\end{abstract}

\section{The Role of Non-Communicable Disease in Premature Mortality}

As a consequence of the so-called epidemiologic transition in most parts of the world $[1,2]$, non-communicable diseases (NCDs) constitute an overwhelming majority of global premature mortality $[3,4]$; in fact, the NCDs included as indicators in the World Health Organization Global Action Plan for the Prevention and Control of NCDs 2013-2020 [5] (i.e., cardiovascular disease, cancer, respiratory disease, and diabetes), comprised $70 \%$ of all deaths globally, and $80 \%$ of all premature NCD deaths in 2010 [6]. The reduction of premature mortality from NCDs is also target 3.4 of the United Nations' Sustainable Development Goals [7].

Part of the epidemiological transition, along with the shift from infectious diseases to NCDs, has been the increase of life expectancy $[1,8]$; and in fact, life expectancy

This article is the winner of the EUFAS Award.

\section{KARGER}

(c) 2018 S. Karger AG, Basel

E-Mail karger@karger.com

www.karger.com/ear
Dr. Jürgen Rehm

Institute for Mental Health Policy Research

33 Russell Street, Toronto, ON M5S 2S1 (Canada)

E-Mail jtrehm@gmail.com 
Table 1. Percentage changes in top NCD causes of death in the United States between 2010 and 2015

\begin{tabular}{|c|c|c|c|c|c|}
\hline Cause of death & $\begin{array}{l}\text { International classification } \\
\text { of diseases and related } \\
\text { health problems code }\end{array}$ & $\begin{array}{l}\text { Age-standardized } \\
\text { death rate per } \\
100,000 \text { in } 2010^{*}\end{array}$ & $\begin{array}{l}\text { Age-standardized } \\
\text { death rate per } \\
100,000 \text { in } 2015^{*}\end{array}$ & $\begin{array}{l}\text { Percentage } \\
\text { change, } \%\end{array}$ & $\begin{array}{l}\text { Rank in } \\
2015\end{array}$ \\
\hline Malignant neoplasms & (C00-C97) & 172.8 & 158.5 & -8.3 & 2 \\
\hline Chronic lower respiratory diseases & $(\mathrm{J} 40-\mathrm{J} 47)$ & 42.2 & 41.6 & -1.4 & 3 \\
\hline Cerebrovascular diseases & (I60-I69) & 39.1 & 37.6 & -3.8 & 5 \\
\hline Total NCD (based on above) & & 454.0 & 427.5 & -5.8 & \\
\hline
\end{tabular}

has been increasing in most countries over the past decades $[9,10]$. Given this situation, it is hard to imagine that life expectancy in a major country will be decreasing despite progress in NCD mortality. Yet, we seem to face this situation for the United States in current years. In the following sections, we discuss the current trends in life expectancy in the United States, and analyze causal influencing factors on these trends.

\section{Trends in Life Expectancy and Premature Mortality in the United States}

The most recent data on life expectancy for the United States showed a stagnation over the past 5 years [11-13], with some populations like middle-aged white non-Hispanics or people living in rural areas experiencing increasing mortality rates and decreasing life expectancy $[14,15]$.

This stagnation in life-expectancy was evident despite sizable declines in mortality between 2010 and 2015 in the major NCDs (Table 1). In fact, 4 of the 5 most important non-communicable causes of death in the United States decreased in age-standardized mortality rates (diseases of the heart, malignant neoplasms, chronic lower respiratory diseases, cerebrovascular diseases), with only the age-standardized rates of diabetes mellitus, the relatively least important cause of death, increasing $[12,16]$.

Years of potential life lost (YLLs) are more closely related to life expectancy than mortality rates. Table 2 gives an overview of YLLs before the age of 75 by cause of death between 2010 and 2015, based on the recent overview publication of the National Center for Health Statistics [13]. In this measure, the overall YLLs for NCDs went down, mainly driven by decreases in cancer mortality and - to a lesser degree - heart disease mortality. YLLs due to the smaller categories of chronic lower respiratory diseases and diabetes increased.

\section{What Causes of Death Were Associated with Increases in Premature Mortality?}

In this section, we discuss the causes of death mainly related to increases in YLLs. We will concentrate on the links to psychoactive substance use as risk factors (overviews on psychoactive substances as risk factors: for alcohol see [17]; for illicit drugs see [18]; for tobacco see [19]). Alcohol and tobacco use are major risk factors for the 4 most important NCDs in the World Health Organization Global Action Plan for the Prevention and Control of NCDs [5], but, as will be shown below, both of these substances and other psychoactive substances are also causally related to other NCD causes of death such as liver cirrhosis or mental disorders [20], as well as in communicable disease and injury mortality [17-19].

The largest contributor to YLL increases in the United States was unintentional injuries (Table 2). A causal link between alcohol use and all kinds of unintentional injuries has been established for a long time [21, 22], with relatively high attributable fractions $[23,24]$. In addition, pharmaceutical and illicit drug use has been linked to many types of unintentional injuries [18], in particular, traffic injuries [25]. For the United States specifically, poisonings were important, and various kinds of psychoactive substances played a key role there (especially pharmaceutical and illicit drugs: [26]; but also alcohol: [27]). As can be seen in Table 2, YLLs from poisonings had a huge increase in the past 5 years. 
Table 2. YLL before age 75 for selected major causes of death United States 2010 and 2015 and proportional change

\begin{tabular}{|c|c|c|c|c|}
\hline Cause of death & $\begin{array}{l}\text { Age-standardized } \\
\text { YLLs* } 2010\end{array}$ & $\begin{array}{l}\text { Age-standardized } \\
\text { YLLs* } 2015\end{array}$ & $\begin{array}{l}\text { Proportional } \\
\text { change, } \%\end{array}$ & ICD code \\
\hline All causes & 6,643 & 6,758 & 1.7 & \\
\hline \multicolumn{5}{|l|}{ Causes of death with decreased YLLs } \\
\hline Malignant neoplasms & 1,396 & 1,283 & -8.1 & $\mathrm{C} 00-\mathrm{C} 97$ \\
\hline Trachea, bronchus, and lung & 331 & 273 & -17.5 & C33-C34 \\
\hline Breast & 262 & 242 & -7.8 & C50 \\
\hline Diseases of heart & 972 & 957 & -1.6 & $\begin{array}{l}\text { I00-I09, I11, } \\
\text { I13, I20-I51 }\end{array}$ \\
\hline Ischemic heart disease & 577 & 530 & -8.1 & $\mathrm{I} 20-\mathrm{I} 25$ \\
\hline Cerebrovascular diseases & 169 & 161 & -4.9 & I60-I69 \\
\hline Nephritis, nephrotic syndrome, and nephrosis & 73 & 69 & -5.2 & $\begin{array}{l}\text { N00-N07, N17-N19, } \\
\text { N25-N27 }\end{array}$ \\
\hline Unintentional injuries & 1,025 & 1,172 & 14.3 & V01-X59, Y85-Y86 \\
\hline Motor vehicle-related injuries & 401 & 405 & 1.1 & $\begin{array}{l}\text { V02-V04, V09.0, V09.2, } \\
\text { V12-V14, V19.0-V19.2, } \\
\text { V19.4-V19.6, V20-V79, } \\
\text { V80.3-V80.5, } \\
\text { V81.0-V81.1, } \\
\text { V82.0-V82.1,V83-V86, } \\
\text { V87.0-V87.8, } \\
\text { V88.0-V88.8, V89.0, V89.2 }\end{array}$ \\
\hline Poisoning & 380 & 531 & 39.9 & $\mathrm{~A} 40-\mathrm{A} 49$ \\
\hline Suicide & 385 & 429 & 11.3 & U03, X60-X84, Y87.0 \\
\hline Homicide & 239 & 252 & 5.4 & U01-U02, X85-Y09, Y87.1 \\
\hline
\end{tabular}

* YLL, years of potential life lost; age-standardization based on US standard population of 2000: [78].

Source: [13].

HIV, human immunodeficiency virus.

Intentional injuries also had marked increases in YLLs over the last 5 years. Suicide mortality has been shown to be causally impacted by alcohol and other psychoactive substance use. Bagge and Sher [28] developed a theoretical framework with complex causal chains for distal and proximal relations. In terms of the epidemiological definition of causality [29, 30], 2 main pathways from substance use to suicide can be distinguished (e.g., [31] specifically for alcohol, but the arguments apply to other substances as well): there is an acute impact of using substances via disinhibition, impulsiveness, and impaired judgment, and substances may also be used as a means to ease the distress associated with committing an act of suicide (e.g., [32]). Furthermore, there is a long-term effect of substance-use disorders on suicide mortality risk, as they can cause high distress often associated with a breakdown of social relations and social marginalization, and without any hope of improvement $[33,34]$. The relative risks for suicide mortality of heavy use of psychoactive substances are high, and the burden of suicide attributable to various substances is only surpassed by the substance-attributable burden due to depression [35].

As for the connection of substance use to intentional injuries from violence and aggression, the evidence can 
be separated between alcohol use and other substances. For the causal impact of alcohol on violence and aggression, there is good evidence, including experimental evidence [36-38]. For illicit drugs, based on the classic paper of Goldstein [38], 3 different types of violence should be distinguished: systemic violence refers to interpersonal aggression among persons involved in the drug trade as a consequence of the illicit market; economic compulsive violence refers to violence in the course of criminal activity to obtain resources to support drug use; and psychopharmacological violence refers to causation of violent behavior by the psychobiological effects of the drug. The latter was most often linked with amphetamines, cocaine, barbiturates, and phencyclidine use, while there is little evidence to link heroin, marijuana, or other hallucinogens.

A 2016 systematic review [39] found some evidence for a connection to systemic violence but little evidence supporting the connection to economic compulsive violence. In addition, reviews have concluded that the evidence for a psychopharmacological causation is weak [40].

The next largest category with respect to increases in YYLs is chronic liver disease and cirrhosis (Table 2), both of which are linked to alcohol use [41], and to drug use via hepatitis infections [42]. Currently, the majority of liver cirrhosis in the United States is estimated to be attributable to alcohol [43]. Chronic lower respiratory diseases follow, which had already been mentioned in the First Surgeon General's Report as being impacted by tobacco use [44]. Next is diabetes, which has been related to alcohol use $[45,46]$, albeit in a curvilinear, $\mathrm{j}$ shaped way for at least some population groups. While lower consumption levels may have protective effects, heavy drinking and alcohol use disorders have detrimental effects ([45-47]; see [48] specifically for the Americas).

Influenza and pneumonia are impacted by alcohol and tobacco use $[49,50]$. Finally, Alzheimer's disease and all forms of dementia are impacted by alcohol use, especially heavy alcohol use [51]. The YLLs for Alzheimer's disease and all forms of dementia are relatively small in absolute terms, as these diseases often occur late in life. However, a recent analysis of French hospitalization data in more than 30 million patients revealed, that while the overall alcohol-attributable fraction for dementia was low, more than $50 \%$ of all early onset dementias (defined as onset before age 65 years) were either alcohol-related dementias $[52,53]$, or in people with alcohol use disorders [54]. In other words, in the age groups impacting life expectancy, alcohol was a major risk factor for all types of dementia.

The importance of substance use was also underlined by causes of death being $100 \%$ attributable to alcohol or drug use (not displayed in Table 2), which increased markedly over the past years (between 2010 and 2014 by 19 and $16 \%$ for drug-attributable and alcohol-attributable causes of death respectively [55]).

In sum, almost all the major causes of death contributing to YLLs (exception: diabetes) were causally and strongly detrimentally linked to the use of psychoactive substances, and thus, such substance use seems to play a major role in the declining life expectancies in the United States (see [56], for other examples of reversals of trends in life expectancy due to substance use). This does not mean that other risk factors are not involved in impacting the current mortality patterns, both in interaction with substance use [57] and as independent risk factor [58]. To give but an example: high body mass index is a risk factor with one of the fastest rising attributable disease burden over the past decades globally [58] and for the United States (own calculations based on [59]) and is also related to a number of disease outcomes discussed above. Examples for the impact of body mass index would be chronic liver disease and cirrhosis [60] or diabetes [58], the former probably in interaction with alcohol use [61].

\section{The Role of Socioeconomic Status}

Socioeconomic status plays an increasing and crucial role in the recent developments of life expectancy [62]. Between 2001 and 2014, the life expectancy at age 40 of the highest income quartile increased by around 0.2 years per year, whereas the increases for the lowest income quartile were only by 0.1 years or less. Throughout this period, the $1 \%$ with the highest income could on average expect to live about 15 (men) and 10 years (women) longer at age 40 than a person of the bottom $1 \%$.

A widening of the socioeconomic gap in mortality in the United States has been observed in several studies over the past decades, particularly in middle-aged people $[14,63]$. While all-cause mortality was decreasing in middle-aged people with more than secondary education, the opposite was true for people with a high school degree or less schooling [14]. The increase in mortality was found to be particularly high in unintentional injuries including poisonings, closely followed by intentional self-harm and chronic liver cirrhosis [14]. Research on injury mortality 
among youth in the United States showed high disparities in homicide and unintentional injury mortality with at least twofold mortality rates among more deprived youth [64]. Similar results were found among the general population with increased risks of unintentional injuries, suicide, and homicide for people from more deprived areas [63]. Furthermore, socioeconomic inequalities in motor vehicle fatalities in the United States increased strongly from 1995 to 2010 [65]. While the fatality rates per miles travelled dropped in socioeconomic groups with higher education, fatalities among persons with less than high school education increased.

Chronic liver disease and cirrhosis as well as diabetes mortality were also associated with trends for a widening the gap between the lower and higher socioeconomic status $[63,66]$. Rate ratios for both conditions increased from around 1.5 in the early 1990s to 2.0 (2005-2009) [63]. Overall, these findings indicate that stagnation and decline in life expectancy are, to a large extent, at the expense of people of lower socioeconomic status.

Substance use is likely to play a key role in these developments. Smoking-attributable mortality [67], overdose deaths from prescription drugs $[68,69]$, as well as alcohol-attributable mortality [70] have been clearly linked to the socioeconomic status.

To give further examples, the prevalence of current smoking overall decreased between 2005 and 2015 by $28 \%$. However, declines were much stronger among people with high socioeconomic status, exacerbating socioeconomic differences that already existed [71]. The findings regarding the prevalence of alcohol use and heavy episodic drinking in different socioeconomic groups in the United States are mixed [72, 73]. Some research found people of lower socioeconomic status to be more likely to drink 5 dirks or more on a drinking occasion compared to people of high socioeconomic status [74]. However, alcohol use has been discussed as a factor that contributes to socioeconomic differences in mortality above and beyond differences in patterns of drinking [57].

A recent study from the United States supports the relevance of alcohol and other substance use for the socioeconomic mortality gap, showing that about $70 \%$ of the socioeconomic differences in mortality could be explained by tobacco and alcohol use, and by physical inactivity [74]. Overall, the evidence suggests that increases in socioeconomic differences in mortality are contributing to the stagnating life expectancy and that these changes are strongly influenced by substance use and related causes of death.

Substance Use and Life Expectancy

\section{Conclusions for Substance Use Policies}

Substance use has been shown to be implicated in the current stagnation of life expectancy in the United States, and this impact was clearly more pronounced for lower socioeconomic strata than for higher socioeconomic strata. What are the consequences for substance use policies? Currently, most such policies are examined for the effectiveness or cost-effectiveness in reducing substance-related harm (see for example, the so-called best buys for reducing substance-attributable disease burden - $[75,76])$. However, in future, in addition to effectiveness and cost-effectiveness, we need to examine the impact of any policy on the premature mortality gap between lower and higher socioeconomic strata. In fact, given the results of our analyses and general considerations on governance for psychoactive substances [77], the ability to reduce the premature mortality may be the most important criterion to choose between overall cost-effective interventions. Otherwise, we may be left with a situation, where the overall disease harm by such substances increases strongly despite stagnating or only moderately increasing prevalence of use (e.g., for alcohol [78]).

\section{Disclosure Statement}

Both authors declare no conflict of interest. This contribution did not receive any specific funding.

\section{Ethics Statement}

This contribution did neither involve human subjects nor animals. It is based only on published population level statistics and thus no ethical review was required.

References

1 Omran AR: The epidemiologic transition. A theory of the epidemiology of population change. Milbank Mem Fund Q 1971;49:509_ 538.

- Miranda JJ, Kinra S, Casas JP, Davey Smith G, Ebrahim S: Non-communicable diseases in low- and middle-income countries: context, determinants and health policy. Trop Med Int Health 2008;13:1225-1234.

-3 GBD 2016 Mortality Collaborators: Global, regional, and national under-5 mortality, adult mortality, age-specific mortality, and life expectancy, 1970-2016: a systematic analysis for the Global Burden of Disease Study 2016. Lancet 2017;390:1084-1150. 
-4 GBD 2016 Causes of Death Collaborators: Global, regional, and national age-sex specific mortality for 264 causes of death, 1980-2016: a systematic analysis for the Global Burden of Disease Study 2016. Lancet 2017;390:11511210.

5 World Health Organization: Global Action Plan for the Prevention and Control of Noncommunicable Diseases 2013-2020. 2013. http://apps.who.int/iris/bitstre am/10665/94384/1/9789241506236_eng.pdf (accessed January 8, 2018).

6 World Health Organization: Noncommunicable Diseases - Fact Sheet. 2017. http://www. who.int/mediacentre/factsheets/fs355/en/ (accessed Decemberl 4, 2017).

7 United Nations: Sustainable Development Goal 3: Ensure Healthy Lives and Promote Well-Being for All at All Ages. 2016. https:// sustainabledevelopment.un.org/sdg3 (accessed January 8, 2018).

8 McKeown RE: The Epidemiologic transition: changing patterns of mortality and population dynamics. Am J Lifestyle Med 2009;3(1 suppl):19S-26S.

9 Riley JC: Rising Life Expectancy: A Global History. Cambridge, Cambridge University Press, 2001.

$\checkmark 10$ Deaton A: The Great Escape - Health, Wealth and the Origins of Inequality. Princeton, Princeton University Press, 2013.

-11 Kochanek KD, Murphy SL, Xu J, Tejada-Vera B: Deaths: final data for 2014. Natl Vital Stat Rep 2016;65:1-122.

-12 Xu J, Murphy SL, Kochanek KD, Arias E: Mortality in the United States, 2015. NCHS Data Brief 2016;267:1-8.

13 National Center for Health Statistics: Health, United States, 2016: with Chartbook on Longterm Trends in Health (DHHS Publication 2017-1232).

14 Case A, Deaton A: Rising morbidity and mortality in midlife among white non-Hispanic Americans in the 21st century. Proc Natl Acad Sci U S A 2015;112:15078-15083.

-15 Shiels MS, Chernyavskiy P, Anderson WF, Best AF, Haozous EA, Hartge P, Rosenberg PS, Thomas D, et al.: Trends in premature mortality in the USA by sex, race, and ethnicity from 1999 to 2014: an analysis of death certificate data. Lancet 2017;389:1043-1054.

16 Murphy SL, Xu J, Kochanek KD: Deaths: Final data for 2010. Natl Vital Stat Rep 2013;61: 1-117.

17 Rehm J, Gmel GE Sr, Gmel G, Hasan OSM, Imtiaz S, Popova S, Probst C, Roerecke M, et al: The relationship between different dimensions of alcohol use and the burden of disease - an update. Addiction 2017;112: 968-1001.

18 Babor T, Caulkins J, Fischer B, Foxcroft D, Humphreys K, Medina-Mora ME, Obot I, Rehm J, et al: Drug Policy and the Public Good (ed 2). Oxford, Oxford University Press, 2018.

19 US Department of Health and Human Services: The Health Consequences of Smok- ing-50 Years of Progress: A Report of the Surgeon General. Atlanta, GA, Department of Health and Human Services. Centers for Disease Control and Prevention. National Center for Chronic Disease Prevention and Health Promotion. Office on Smoking and Health, 2014.

20 Lopez AD, Williams TN, Levin A, Tonelli M, Singh JA, Burney PG, Rehm J, Volkow ND, et al: Remembering the forgotten non-communicable diseases. BMC Med 2014;12:200.

21 Rehm J, Baliunas D, Borges GL, Graham K, Irving $\mathrm{H}$, Kehoe T, Parry CD, Patra J, et al: The relation between different dimensions of alcohol consumption and burden of disease: an overview. Addiction 2010;105:817-843.

22 Cherpitel CJ: Alcohol and injuries: a review of international emergency room studies. Addiction 1993;88:923-937.

23 Cherpitel CJ, Ye Y, Bond J, Borges G, Monteiro M, Chou P, Hao W: Alcohol attributable fraction for injury morbidity from the doseresponse relationship of acute alcohol consumption: emergency department data from 18 countries. Addiction 2015;110:1724-1732.

24 World Health Organization: Global Status Report on Alcohol and Health. Geneva, World Health Organization, 2014.

25 Elvik R: Risk of road accident associated with the use of drugs: a systematic review and meta-analysis of evidence from epidemiological studies. Accid Anal Prev 2013;60: 254-267.

26 Centers for Disease Control and Prevention: NCHS Data on Drug-poisoning deaths. 2017. https://www.cdc.gov/nchs/data/factsheets/ factsheet_drug_poisoning.htm (accessed December 18, 2017).

27 Centers for Disease Control and Prevention: Alcohol Poisoning Deaths. 2015. https:// www.cdc.gov/vitalsigns/alcohol-poisoningdeaths/index.html (accessed December 18, 2017).

28 Bagge CL, Sher KJ: Adolescent alcohol involvement and suicide attempts: toward the development of a conceptual framework. Clin Psychol Rev 2008;28:1283-1296.

29 Rothman KJ, Greenland S, Lash TL: Modern Epidemiology, ( ed 3). Philadelphia, Lippincott Williams \& Wilkins, 2008.

30 Rehm J, Taylor B, Patra J, Gmel G: Avoidable burden of disease: conceptual and methodological issues in substance abuse epidemiology. Int J Methods Psychiatr Res 2006;15: 181-191.

31 Pompili M, Serafini G, Innamorati M, Dominici G, Ferracuti S, Kotzalidis GD, Serra G, Girardi P, et al: Suicidal behavior and alcohol abuse. Int J Environ Res Public Health 2010; 7:1392-1431.

32 Borges G, Bagge CL, Cherpitel CJ, Conner KR, Orozco R, Rossow I: A meta-analysis of acute use of alcohol and the risk of suicide attempt. Psychol Med 2017;47:949-957.

-33 Vijayakumar L, Kumar MS, Vijayakumar V: Substance use and suicide. Curr Opin Psychiatry $2011 ; 24: 197-202$.
34 Wilcox HC, Conner KR, Caine ED: Association of alcohol and drug use disorders and completed suicide: an empirical review of cohort studies. Drug Alcohol Depend 2004; 76(suppl):S11-S19.

35 Ferrari AJ, Norman RE, Freedman G, Baxter AJ, Pirkis JE, Harris MG, Page A, Carnahan E, et al.: The burden attributable to mental and substance use disorders as risk factors for suicide: findings from the Global Burden of Disease Study 2010. PLoS One 2014;9:e91936.

36 Rehm J, Room R, Monteiro M, Gmel G, Graham K, Rehn N, Sempos CT, Frick U, et al: Alcohol use; in Ezzati M, Lopez AD, Rodgers A, Murray CJL (eds): Comparative Quantification of Health Risks: Global and Regional Burden of Disease Attributable to Selected Major Risk Factors. Geneva, World Health Organization, 2004, pp 959-1109.

37 Bushman BJ, Cooper HM: Effects of alcohol on human aggression: an integrative research review. Psychol Bull 1990;107:341-354.

38 Goldstein PJ: The drugs/violence nexus: a tripartite conceptual framework. J Drug Issues 1985;15:493-506.

- 39 Ives TJ, Chelminski PR, Hammett-Stabler CA, Malone RM, Perhac JS, Potisek NM, Shilliday BB, Dewalt DA, et al: Predictors of opioid misuse in patients with chronic pain: a prospective cohort study. BMC Health Serv Res 2006;6:46.

40 Kuhns JB, Clodfelter TA: Illicit drug-related psychopharmacological violence: The current understanding within a causal context. Aggress Violent Behav 2009;14:69-78.

41 Rehm J, Taylor B, Mohapatra S, Irving H, Baliunas D, Patra J, Roerecke M: Alcohol as a risk factor for liver cirrhosis: a systematic review and meta-analysis. Drug Alcohol Rev 2010; 29:437-445.

42 Blachier M, Leleu H, Peck-Radosavljevic M, Valla DC, Roudot-Thoraval F: The burden of liver disease in Europe: A review of available epidemiological data. J Hepatol 2013;58:593608.

43 Rehm J, Kehoe T, Gmel G, Stinson F, Grant B, Gmel G: Statistical modeling of volume of alcohol exposure for epidemiological studies of population health: the US example. Popul Health Metr 2010;8:3.

44 US Department of Health - Education and Welfare: Smoking and Health: Report of the Advisory Committee to the Surgeon General of the Public Health Service. Washington, US Department of Health - Education and Welfare, 1964.

45 Knott C, Bell S, Britton A: Alcohol consumption and the risk of type 2 diabetes: a systematic review and dose-response meta-analysis of more than 1.9 million individuals from 38 observational studies. Diabetes Care 2015;38: 1804-1812.

46 Baliunas DO, Taylor BJ, Irving H, Roerecke M, Patra J, Mohapatra S, Rehm J: Alcohol as a risk factor for type 2 diabetes: a systematic review and meta-analysis. Diabetes care 2009; 32:2123-2132. 
-47 Roerecke M, Rehm J: Cause-specific mortality risk in alcohol use disorder treatment patients: a systematic review and meta-analysis. Int J Epidemiol 2014;43:906-919.

- 48 Babor T, Rehm J, Jernigan D, Vaeth P, Monteiro M, Lehman H: Alcohol, diabetes, and public health in the Americas. Rev Panam Salud Publica 2012;32:151-155.

49 Samokhvalov AV, Irving HM, Rehm J: Alcohol consumption as a risk factor for pneumonia: a systematic review and meta-analysis. Epidemiol Infect 2010;138:1789-1795.

50 US Department of Health and Human Services: The health consequences of smoking-50 years of progress: a report of the surgeon general. Indian J Med Sci 2014;63:520-533.

51 Schwarzinger M, Thiébaut SP, Baillot S, Mallet V, Rehm J: Alcohol use disorders and associated chronic disease - a national retrospective cohort study from France. BMC Public Health 2017;18:43.

52 Ridley NJ, Draper B, Withall A: Alcohol-related dementia: an update of the evidence. Alzheimers Res Ther 2013;5:3.

-53 Oslin D, Atkinson RM, Smith DM, Hendrie $\mathrm{H}$ : Alcohol related dementia: proposed clinical criteria. Int J Geriatr Psychiatry 1998;13: 203-212.

- 54 Schwarzinger M, Pollock BG, Hasan OSM, Dufouil C, Rehm J: Contribution of alcohol use disorders to the burden of dementia in France 2008-2013: a nationwide retrospective cohort study. Lancet Public Health 2018, epub ahead of print.

55 Imtiaz S, Probst C, Rehm J: Substance use and population life expectancy in the United States: Interactions with health inequalities and implications for policy. Drug Alcohol Rev, in press.

-56 Rehm J, Anderson P, Fischer B, Gual A, Room R: Policy implications of marked reversals of population life expectancy caused by substance use. BMC Med 2016;14:42.

57 Rehm J, Probst C: What about drinking is associated with shorter life in poorer people? PLoS Med 2018; 15:e1002477.

- 58 GBD 2016 Risk Factors Collaborators: Global, regional, and national comparative risk assessment of 84 behavioural, environmental and occupational, and metabolic risks or clusters of risks, 1990-2016: a systematic analysis for the Global Burden of Disease Study 2016. Lancet 2017;390:1345-1422.
59 Institute for Health Metrics and Evaluation: GBD Compare. 2016. https://vizhub.healthdata.org/gbd-compare/ (accessed March 1, 2018).

60 Milic S, Lulic D, Stimac D: Non-alcoholic fatty liver disease and obesity: biochemical, metabolic and clinical presentations. World J Gastroenterol 2014;20:9330-9337.

61 Roerecke M, Nanau R, Rehm J, Neuman M: Ethnicity matters: a systematic review and meta-analysis of the non-linear relationship between alcohol consumption and prevalence and incidence of hepatic steatosis. EBioMedicine 2016;8:317-330

62 Chetty R, Stepner M, Abraham S, Lin S, Scuderi B, Turner N, Bergeron A, Cutler D: The Association between income and life expectancy in the United States, 2001-2014. JAMA 2016;315:1750-1766.

63 Singh GK, Siahpush M: Widening rural-urban disparities in all-cause mortality and mortality from major causes of death in the USA, 1969-2009. J Urban Health 2014;91: 272-292.

64 Singh GK, Azuine RE, Siahpush M, Kogan MD: All-cause and cause-specific mortality among US youth: socioeconomic and ruralurban disparities and international patterns. J Urban Health 2013;90:388-405.

65 Harper S, Charters TJ, Strumpf EC: Trends in socioeconomic inequalities in motor vehicle accident deaths in the United States, 1995-2010. Am J Epidemiol 2015;182:606614.

66 Saydah S, Lochner K: Socioeconomic Status and Risk of Diabetes-Related Mortality in the U.S. Public Health Rep 2010;125:377-388.

67 Choi SH, Stommel M: Impact of age at smoking initiation on smoking-related morbidity and all-cause mortality. Am J Prev Med 2017; 53:33-41.

68 Lanier WA, Johnson EM, Rolfs RT, Friedrichs MD, Grey TC: Risk factors for prescription opioid-related death, Utah, 2008-2009. Pain Med 2012;13:1580-1589.

69 Hall AJ, Logan JE, Toblin RL, Kaplan JA, Kraner JC, Bixler D, Crosby AE, Paulozzi LJ: Patterns of abuse among unintentional pharmaceutical overdose fatalities. JAMA 2008;300: 2613-2620.

70 Probst C, Roerecke M, Behrendt S, Rehm J: Socioeconomic differences in alcohol-attributable mortality compared with all-cause mortality: a systematic review and metaanalysis. Int J Epidemiol 2014;43:13141327.

-71 Jamal A, Homa DM, O’Connor E, Babb SD Caraballo RS, Singh T, Hu SS, King BA: Current cigarette smoking among adults - United States, 2005-2014. MMWR Morb Mortal Wkly Rep 2015;64:1233-1240.

72 Centers for Disease Control and Prevention (CDC): Vital signs: binge drinking prevalence, frequency, and intensity among adults - United States, 2010. MMWR Morb Mortal Wkly Rep 2012;61:14-19.

-73 Patrick ME, Wightman P, Schoeni RF, Schulenberg JE: Socioeconomic status and substance use among young adults: a comparison across constructs and drugs. J Stud Alcohol Drugs 2012;73:772-782.

-74 Nandi A, Glymour MM, Subramanian SV: Association among socioeconomic status, health behaviors, and all-cause mortality in the United States. Epidemiology 2014;25: 170-177.

75 World Health Organization: "Best Buys" and other Recommended Interventions for the Prevention and Control of Noncommunicable Diseases. 2017. http://who.int/ncds/management/WHO_Appendix_BestBuys.pdf (accessed January 9, 2018).

76 Chisholm D, Moro D, Bertram M, Pretorius C, Gmel G, Shield K, Rehm J: Are the "best buys" for alcohol control still valid? An update on the comparative cost-effectiveness of alcohol control strategies at the global level. J Stud Alcohol Drugs, in press.

77 Anderson P, Braddick F, Conrod P, Gual A, Hellman M, Matrai S, Miller D, Nutt D, et al: The New Governance of Addictive Substances and Behaviours. Oxford, Oxford University Press, 2017.

78 Grant BF, Chou SP, Saha TD, Pickering RP, Kerridge BT, Ruan WJ, Huang B, Jung J, et al: Prevalence of 12-Month Alcohol Use, High-Risk Drinking, and DSM-IV Alcohol Use Disorder in the United States, 20012002 to 2012-2013: results from the national epidemiologic survey on alcohol and related conditions. JAMA Psychiatry 2017;74:911923.

79 National Cancer Institute: Standard Populations - 19 Age Groups. 2017. https://seer.cancer.gov/about/contact.html (accessed December 15, 2017). 